\section{Do patients receiving haemodialysis need folic acid supplements?}

Patients receiving regular haemodialysis may be at risk of developing folic acid deficiency because foods rich in the vitamin must often be restricted and loss of the vitamin across the dialysis membrane is likely to occur because of its low molecular weight and only moderate protein binding. ${ }^{2}$ We undertook two studies to assess the need for giving folic acid to patients receiving haemodialysis.

\section{Patients, methods, and results}

STUDY 1

Loss of folic acid during a seven-hour dialysis was measured in 15 patients, none of whom were taking supplementary folic acid. A single pass system with a $1.0 \mathrm{~m}^{2}$ Meltec Multipoint dialyser and $11.5 \mu \mathrm{m}$ thickness Cuprophan membranes was used, blood and dialysate flow rates being 220 and $500 \mathrm{ml} /$ min respectively. Blood samples were taken from the afferent ("arterial") and efferent ("venous") dialyser lines after 30 minutes' dialysis and again after six and a half hours. The means of the two arterial and two venous serum folate concentrations were used to calculate the total loss for each patient. Serum folate concentration was measured in quintuplicate, using a competitive binding assay (Becton Dickinson Folate Radioassay kit; intraassay coefficient of variation $5.9 \%$ )

The mean afferent dialyser line ("arterial") serum folate concentration fell significantly from $4.31+\mathrm{SEM} 0.47$ to $3.49+0.38 \mu \mathrm{g} / \mathrm{l}$ during the six hours' dialysis $(p<0.01)$. The median loss of folate into the dialyser was $37 \cdot 3 \mu \mathrm{g}$ (range $3 \cdot 6-91.5 \mu \mathrm{g}$ ).

\section{STUDY 2}

The relation between folic acid state and anaemia was examined retrospectively in 72 patients dialysed at home for 6-120 (mean 49) months. All were taking regular oral iron supplements and had normal or raised serum ferritin concentrations. None had received a blood transfusion for at least six months or been treated with folic acid, cobalt chloride, or androgens. Monthly measurements of haemoglobin concentration and mean corpuscular volume, and less frequent measurements of serum folate and red-cell folate concentrations, had been made in all patients. The most recent simultaneous values of these variables were used in the analysis. Blood samples were taken at least 36 hours after the preceding dialysis. Haemoglobin concentration and mean corpuscular volume were measured using a Coulter Counter, and serum folate and red-cell folate concentrations by bioassay using Lactobacillus casei.

Mean haemoglobin concentration was $8 \cdot 13 \pm 0.29 \mathrm{~g} / \mathrm{dl}$, mean corpuscular volume $85 \cdot 28+0.90 \mathrm{fl}$ (normal $77-93 \mathrm{fl}$ ), serum folate concentration $4 \cdot 46 \pm$
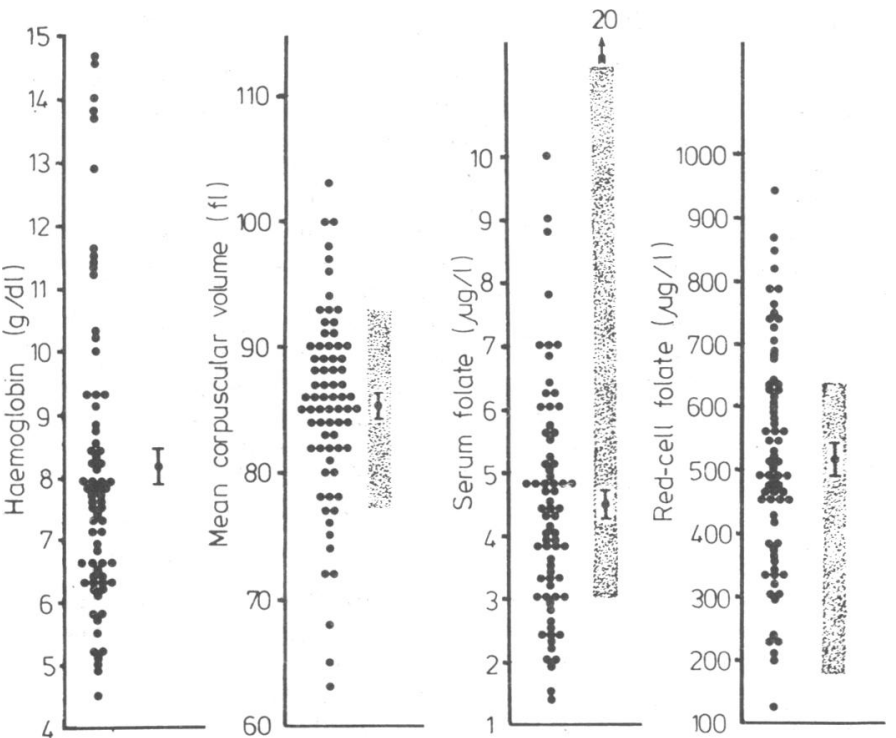

Haematological values in 72 patients, showing mean $\pm S E M$ values. Stippled areas indicate laboratory normal ranges.
$0 \cdot 21 \mu \mathrm{g} / 1$ (normal $3 \cdot 0-20 \cdot 0 \mu \mathrm{g} / \mathrm{l}$ ), and red-cell folate concentration $515 \pm \widehat{\Omega}$ $21 \mu \mathrm{g} / 1$ (normal $180-640 \mu \mathrm{g} / \mathrm{l}$ ) (figure). Serum folate and red-cell folate concentrations correlated significantly $(\mathrm{r}-0.43, \mathrm{p}<0.001$, Pearson correlation), but no association between the other variables was found. In only one $\mathbb{D}$ patient was red-cell folate concentration abnormally low.

In a subgroup of seven patients with macrocytosis haemoglobin, serum folate, and red-cell folate concentrations were not significantly different from:those in the remainder. Similarly, in a subgroup of 14 patients with an abnormally low serum folate concentration, mean corpuscular volume and hacmoglobin and red-cell folate concentrations did not differ significantly듣 from those in the other patients.

\section{Comment}

The first study showed that the median loss of folate per dialysis क was $37.3 \mu \mathrm{g}$, equivalent to $16 \mu \mathrm{g}$ daily assuming thrice-weekly dialysis, which is only slightly greater than the urinary loss of about $\overrightarrow{\vec{\omega}}$ $10 \mu \mathrm{g}$ daily in normal subjects. ${ }^{3}$ The second study showed that ${ }^{\circ}$ although serum folate concentration was usually low-normal (mean of $4.46 \mu \mathrm{g} / \mathrm{l}$ ) and subnormal in 14 patients, red-cell folate concentration, which is probably the best single index of folate stores, ${ }^{4}$ was well $N$ maintained (mean $515 \mu \mathrm{g} / \mathrm{l}$ ) and was subnormal in only one patient. N In addition, no patient with a low serum folate concentration had macrocytosis, and haemoglobin concentration in this group was almost identical with that in patients whose serum folate concentration was normal. The dietary folate intake of our patients (33-163 (mean 70) $\overrightarrow{\mathrm{N}}$ $\mu \mathrm{g}$ /day), though close to the minimum daily requirement, ${ }^{5}$ therefore $N$ appears adequate to compensate for their slightly increased loss of the vitamin, and we see no justification for giving folic acid supple- 을 ments to adequately nourished patients receiving haemodialysis.

We thank the nursing staff, Hanbury dialysis unit; Mr P C Hall, senior chief technician, department of haematology; and Miss J F Jeffery for their help.

${ }^{1}$ Johns DG, Sperti S, Burgen ASV. The metabolism of tritiated folic $\stackrel{\infty}{\rightarrow}$ acid in man. 7 Clin Invest $1961 ; 40: 1684-95$.

2 Soliman HA, Loesen H. Folic acid binding by human plasma albumin. Scand $\mathcal{f}$ Clin Lab Invest $1976 ; 36: 299-304$.

${ }^{3}$ Spray GH, Fourman P, Witts LJ. The excretion of small doses of folic acid. Br Med f 1951 ;ii :202-5.

4 Chanarin I. The megaloblastic anaemias. Oxford: Blackwell Scientific $\frac{O}{\mathbb{Q}}$ Publications, 1979.

${ }^{5}$ Herbert V. Minimal daily adult folate requirement. Arch Intern Med $\overrightarrow{\vec{D}}$ $1962 ; 110: 649-52$

(Accepted 29 fanuary 1981)

Department of Nephrology, The London Hospital, London E1 1 BB J CUNNINGHAM, BM, MRCP, lecturer

V L SHARMAN, MB, MRCP, senior registrar

F J GOODWIN, MD, FRCP, consultant nephrologist

F P MARSH, MB, FRCP, consultant nephrologist

\section{Hypothermia and hypotension in Hodgkin's disease}

The presence of excessive night sweats, fever, and weight loss of more than $10 \%$ of the patient's normal weight determines the stage, treatment method, and prognosis in patients with Hodgkin's disease. $\mathbb{\Phi}$ I report a patient with Hodgkin's disease who developed hypothermia and hypotension and responded favourably to combination chemotherapy.

\section{Case report}

A 22-year-old man presented in September 1977 with a five-month history of excessive night sweats, $12.7 \mathrm{~kg}$ weight loss, and a swelling in the left upper abdomen. Examination showed no abnormality except an enlarged spleen. Blood tests showed a haemoglobin concentration of $10 \mathrm{~g} / \mathrm{dl}$, normal $\overline{\mathrm{Q}}$ 
white blood cell and platelet counts, raised erythrocyte sedimentation rate, and increased $\alpha_{2}$-globulin and decreased gammaglobulin concentrations. Liver function tests were grossly abnormal. Bone-marrow biopsy specimen were normal. Laparotomy showed an enlarged and abnormal liver, gross para-aortic lymphadenopathy, and splenomegaly. Splenectomy, liver biopsy, and lymph-node biopsy showed Hodgkin's disease of mixed cellularity type.

During his two-week stay in hospital for investigation, and before operation, his core temperature slowly but steadily fell to $29^{\circ} \mathrm{C}$. Blood pressure also dropped to $60 \mathrm{~mm} \mathrm{Hg}$ systolic and $40 \mathrm{~mm} \mathrm{Hg}$ diastolic. There was no shivering. Laboratory investigations excluded hypothyroidism, hypoglycaemia, hypopituitarism, and hypoadrenalism as possible causes. There was no history of trauma or drug ingestion. Computed tomography of the brain showed no evidence of intracranial deposits. Blood culture showed no organisms, thus excluding possible causes of hypothermia.

Combination chemotherapy with nitrogen mustard $10 \mathrm{mg}$, vincristine $2 \mathrm{mg}$ intravenously on days 1 and 8 , and procarbazine $150 \mathrm{mg}$ and prednisone $40 \mathrm{mg}$ by mouth daily for two weeks was started. Within a few days his temperature and blood pressure had returned to normal. After he had completed six courses, with a three-week interval between courses, megavoltage radiotherapy to the para-aortic, common iliac, and external iliac lymph nodes was given using the inverted $\mathrm{Y}$ technique.

He subsequently remained free of Hodgkin's disease, although he later developed necrosis of the head of the left femur.

\section{Comment}

To my knowledge hypothermia or hypotension, or both, have not been described in association with Hodgkin's disease. This case suggests that such an association is possible. There was no shivering, thus excluding a peripheral cause for the hypothermia. The absence of metabolic disease, hypothalamic or central nervous system dysfunction, trauma, or history of drug ingestion suggests that the hypothermia and hypotension were related to the Hodgkin's disease, and the immediate recovery with chemotherapy substantiates this.

Spread to the hypothalamus in Hodgkin's disease, despite the absence of clinical or radiological evidence, remains a possibility and could result through its anatomical proximity to the source of thermoregularity problems. The developing hypothermia may produce hypotension, as described by Reuler.

Hypothermia and hypotension in a patient with Hodgkin's disease, should be treated with chemotherapy. The response in this patient was dramatic. Unless appropriate treatment is started permanent damage from the hypothermia may result. ${ }^{1}$

I thank Mrs G Goodall for typing the manuscript.

${ }^{1}$ Reuler JB. Hypothermia: pathophysiology, clinical settings, and management. Ann Intern Med 1978;89:519-27.

(Accepted 2 February 1981)

Regional Radiotherapy Centre, Newcastle General Hospital, Newcastle upon Tyne NE4 6BE

OSAMA M KORIECH, MD, consultant radiotherapist

\section{Transcervical thymectomy and thymus remnants}

Excision of the thymus for treatment of myasthenia gravis became popular after it was suggested that the disease might have an autoimmune origin. Initially the thymus was resected through the sternum or a similar approach was used. The procedure was accompanied by some surgical and postoperative risks and inconvenience including prolonged intubation and often tracheostomy. A simpler procedure for removing a thymus that was not enlarged-namely, transcervical thymectomy-was proposed by Kirschner et $a l^{1}$ in 1969. Since it carried a much lower morbidity it was widely accepted, and we subsequently used it in 61 cases. Recently we reviewed these 61 patients to study the possibility that remnants of thymus might be present in those in whom the myasthenia had progressed unfavourably. To do this we performed lateral $x$-ray tomography of the anterior mediastinum after injecting air $(10 \mathrm{ml} / \mathrm{kg}$ body weight). We were surprised to find a typical thymic shadow in 14 out of 19 patients studied. Some of these patients subsequently underwent a second operation-trans-sternal thymectomy-and the following case report is typical.

\section{Case report}

This 31-year-old woman had suffered from myasthenia gravis since the age of 23 years. When 24 she had undergone transcervical thymectomy after air tomography of the anterior mediastinum had shown a shadow suggestive of thymus enlargement (figure (top)). At operation a bilobar, well-encapsulated mass was extirpated. Pathological study showed two roughly cylindrical pieces of tissue $3 \mathrm{~cm}$ long and $0.8 \mathrm{~cm}$ wide united by the capsule and weighing $20 \mathrm{~g}$. The histological diagnosis was thymic tissue with numerous germinal centres -that is, thymic hyperplasia. The postoperative course was uneventful, and in the following months muscle weakness was moderately improved for some time; doses of anticholinesterase drugs were the same as she had been receiving before operation.

When she was 31 years old air tomography showed a mediastinal shadow compatible with thymic enlargement (figure (bottom)). A 21-g encapsulated mass was removed from the anterior mediastinum at trans-sternal thymectomy. Histological study showed that the mass was thymic tissue with numerous germinal centres. No complications occurred after the operation.

\section{Comment}

The findings in the reported case are similar to those observed in other patients in our series. At least two possibilities may explain them. One is that not all the thymus was removed at the first operation

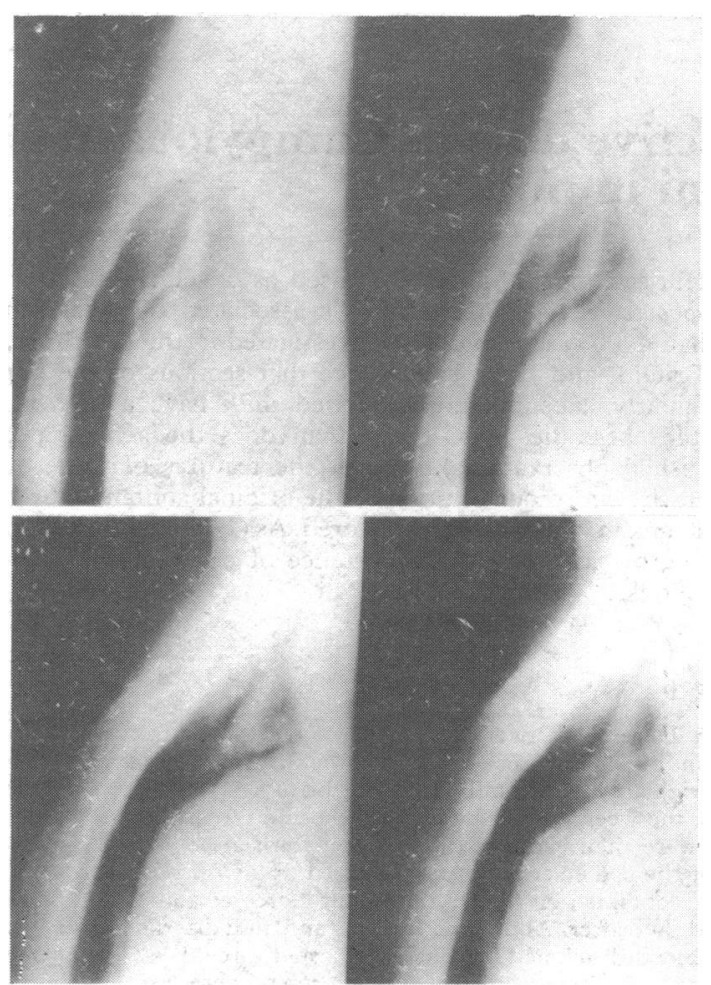

Air tomogram of anterior mediastinum before transcervical thymectomy (top) and before trans-sternal thymectomy seven years later (bottom), showing enlargement of thymus.

owing to inadequate exploration or lack of surgical experience with this technique. We do not believe, however, that this was so. In all cases the tissue removed was surrounded by an undamaged capsule and finger exploration of the anterior and superior mediastinum was carefully carried out before closure. The second possibility, which we favour, is the existence of small pieces of thymic tissue unconnected with the main body of the gland. It is feasible that these will become hypertrophic some time after the operation. Residual thymus or recurrent tumour causes myasthenia after removal of asymptomatic thymoma. ${ }^{2}{ }^{3}$ Thymic remnants have been found at re-exploration ${ }^{4}$ and necropsy. ${ }^{2} 5$

We believe that the findings in the reported case, as in several others in our series, point to the need for postoperative evaluation for the presence of thymic tissue after transcervical thymectomy for thymic hyperplasia. An increase in the severity of the disease after partial or total remission may possibly be due to hypertrophy of thymic remnants. If this is so thymectomy by the transcervical approach should 